\title{
Prevalence of map-dot-fingerprint changes in the cornea
}

\author{
THEODORE P. WERBLIN, * LAWRENCE W. HIRST, WALTER J. STARK, \\ AND IRENE H. MAUMENEE \\ From the Wilmer Ophthalmological Institute, Johns Hopkins Hospital, Baltimore, Maryland, USA
}

SUMMARY Map-dot-fingerprint basement-membrane abnormalities of the cornea are common in the general population, affecting as many as $76 \%$ of persons over age 50 and $42 \%$ of persons of all ages. The prevalence of this condition in the general population is not significantly different from that found in families of patients with recurrent corneal erosions and map-dot-fingerprint corneal changes. Despite this extremely high prevalence of basement-membrane changes the incidence of recurrent erosive symptoms in total groups of patients with basement-membrane changes is quite rare, suggesting that these 2 entities are possibly not related. Although previous observers have suggested an autosomal dominant mode of inheritance of these basement-membrane changes, our data raise the possibility that map-dot-fingerprint basement-membrane changes represent an age-dependent, degenerative condition of the cornea. We were unable, however, to prove either hypothesis.

Map-dot-fingerprint abnormalities of the corneal epithelial basement membrane have been the subject of numerous articles and several reviews in recent years. ${ }^{1-3}$ This is largely because of the association of the basement-membrane changes, seen both clinically and microscopically, with recurrent corneal erosions. ${ }^{2-4}$ Some recent reports indicate that these abnormalities of basement membrane constitute a dystrophy with an autosomal dominant mode of inheritance, ${ }^{35}$ whereas others believe it is simply a corneal degeneration. ${ }^{6}$ Guerry $^{7}$ postulated this to be a rare condition seen in approximately 1 in 4000 patients in his files, whereas Laibson ${ }^{3}$ found the prevalence of these basement-membrane changes in the general population to be approximately $6 \%$.

Four years ago we undertook a study of the inheritance of these basement-membrane changes in patients with recurrent erosions. In this initial study we also looked at a small group of people who were not related to patients with recurrent erosions. Because of the high prevalence of map-dot-fingerprint

Presented in part before the annual meeting of the Association for Research in Vision and Ophthalmology, Sarasota, Florida, May 1979.

*Present address: LSU Eye Center, LSU Medical Center School of Medicine, New Orleans, Louisiana, USA.

Correspondence to Dr L. W. Hirst, Wilmer Ophthalmological Institute, Johns Hopkins Hospital, Baltimore, Maryland 21205, USA. changes in this small 'control' group of people we undertook an extensive prospective study of the general population to determine the prevalence of this condition. In this paper we present data from both of these studies.

\section{Subjects and methods}

Data were collected over a 4-year period from 2 separate populations. The first group, which will be referred to as the 'general population' sample, consisted mainly of volunteers from the Baltimore area. The second group, which will be referred to as the 'genetic population', consisted of relatives of patients known to have map-dot-fingerprint changes with recurrent corneal erosions.

\section{GENERAL POPULATION}

People were recruited for this study by means of a poster displayed at the Johns Hopkins Hospital and Medical School. Stipulated on the poster was the fact that a free general eye examination was available for anyone who was not a hospital patient and who was over the age of 18. For the purposes of this study 215 such people were examined. Almost all of these people were unrelated.

GENETIC POPULATION

Relatives of 19 patients who were seen at the Wilmer Institute for recurrent erosions and were found to 
have basement-membrane changes of the map-dotfingerprint type were examined for similar changes. A total of 108 people were examined: the 19 probands, 74 genetic relatives of these probands, and 15 relatives by marriage. One proband and 5 affected members of his family had unique basementmembrane changes. This family is excluded from the data of the genetic population. Also excluded from the genetic population data are the 15 relatives by marriage and the probands.

\section{EXAMINATION}

After a thorough ocular and medical history and a genealogical history in the case of the genetic population the people were questioned directly about any history of corneal erosive or recurrent ocular symptoms. Members of each family were examined together to facilitate observation of any morphological similarities in the basement-membrane changes.

After visual acuity testing and external examination single drops of tropicamide $1 \%$ and phenylephrine $10 \%$ were used to obtain pupillary dilatation. Corneal and anterior segment examinations were completed with direct and retroillumination with a Haag-Streit 900 slit-lamp at high power. The detailed examination of the cornea, done primarily with retroillumination, was of critical importance. Careful attention was given to the identification of debris in the tear film and artefact secondary to opacities in the media not associated with corneal changes. A second observer independently repeated the slit-lamp examination of the cornea. In some cases basement-membrane changes were photographed with a Zeiss photo slit-lamp at setting 40 . Finally, pneumatonometry and indirect ophthalmoscopy of the fundus were performed.

At the conclusion of the corneal examination, but before tonometry, basement-membrane abnormalities noted by the 2 independent observers were compared. $95 \%$ of the lesions were noted independently by both examiners. In the $5 \%$ of cases in which small, usually peripheral lesions were seen by only one examiner the second observer re-examined the cornea. If both agreed that the lesions represented an alteration of basement-membrane, the finding was included in our tabulations. About $1 \%$ of the lesions were considered not to represent basement-membrane changes and were excluded. Any lesion in a patient with a definite history of trauma to an eye with a basement-membrane change was not included. We recorded basement-membrane changes with regard to their morphological types and geographical locations.

Our classification of corneal basement-membrane findings was in accordance with that of previous workers. $^{3589}$ 'Maps' are circumscribed areas of basement membrane whose central regions have a coarse, ground-glass appearance and whose margins appear elevated. They may be quite large, encompassing up to a third or a half of a cornea (Fig. 1a,b,c) or may be quite small-several hundred microns in diameter (Fig. 1d). 'Dots' (micropseudocysts) appear as fine, grey-white opacities in the corneal epithelium (Fig. 1e). Larger pseudocysts are 'irregular in shape but have smooth, rounded edges. ${ }^{3}$ The large pseudocysts can be $1 \mathrm{~mm}$ in diameter, whereas the smaller dots are of the order of $50 \mu \mathrm{m}$. 'Fingerprint' lines (Fig. 1f) are usually multiple, parallel or almost parallel, curvilinear thickenings of basement membrane which often extend over several millimetres. However, they may also occur as single, isolated lines or in small clusters. ${ }^{8}$ 'Bleb' changes consist of 'close-set, flattened, bleb-like excrescences' (Fig. $1 \mathrm{~g}, \mathrm{~h})$. These excrescences are generally round, varying in size from 15 to $100 \mu \mathrm{m}$, and tend to occur in clusters. ${ }^{8}$ 'Tramlines' (Fig. 1i,j) are less common basement-membrane changes which appear to be morphological variants of fingerprints. ' $\mathrm{Nets}$ ' (Fig. $1 \mathrm{k})$ are a 'polygonal pattern' of basement-membrane excrescences, often partially intermixed with blebs. ${ }^{8}$ Sometimes several forms of basement-membrane changes occur in one or in both eyes. ${ }^{8}$ For example, fingerprint lines, nets, and an area of blebs are seen side by side in the cornea shown in Fig. 11.

\section{Results}

GENERAL POPULATION

The age distribution of the general population we studied (Fig. 2) showed a bias toward younger age groups. In fact $38 \%$ of those examined were between the ages of 18 and 30. As to occupation (Fig. 3), $63 \%$ of those examined were secretarial workers, professionals, students, or educators. Most of the people lived in or close to Baltimore (Fig. 4); $59 \%$ lived in Baltimore City and $35 \%$ in surrounding Baltimore County. Most of them had moderate incomes, averaging about $\$ 10000$ annually (Fig. 5). Our sample population was therefore biased toward young people whose occupations made any considerable exposure to environmental trauma unlikely.

Of the 215 patients from the general population $43 \%$ had basement-membrane abnormalities in one or both eyes. There was a $76 \%$ prevalence of these changes in patients over the age of 50 . Bilateral basement-membrane changes were seen in $18 \%$ of these patients and in $47 \%$ of patients over age 50 (Fig. 6.)

'Maps' were by far the most commonly encountered lesion (Table 1). Map-like changes were seen in 49 of the 54 patients with unilateral basement- 


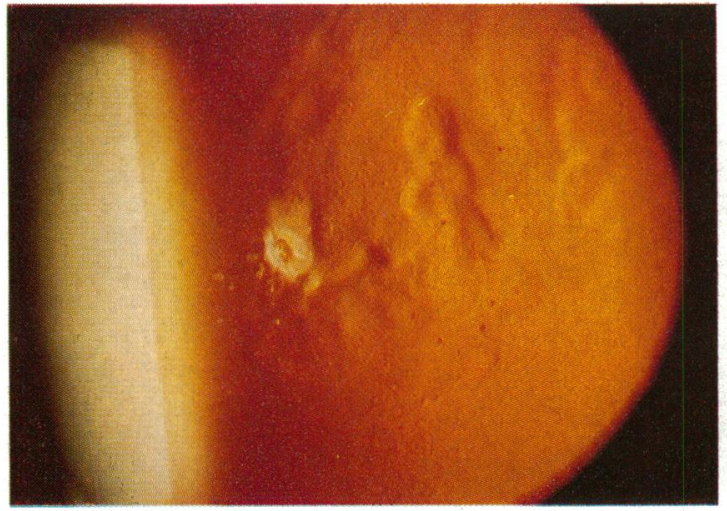

$1 \mathrm{a}$

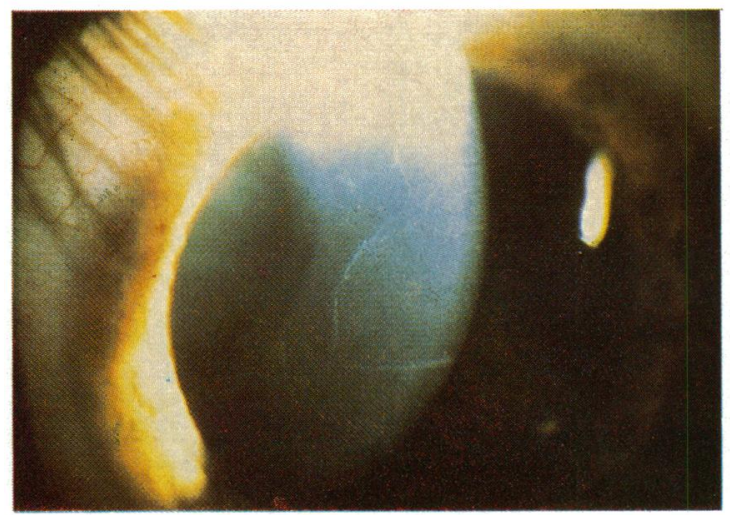

$1 c$

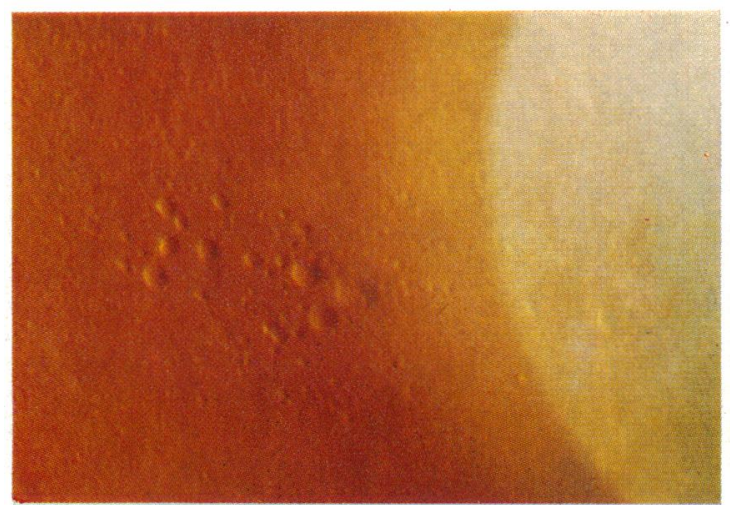

le

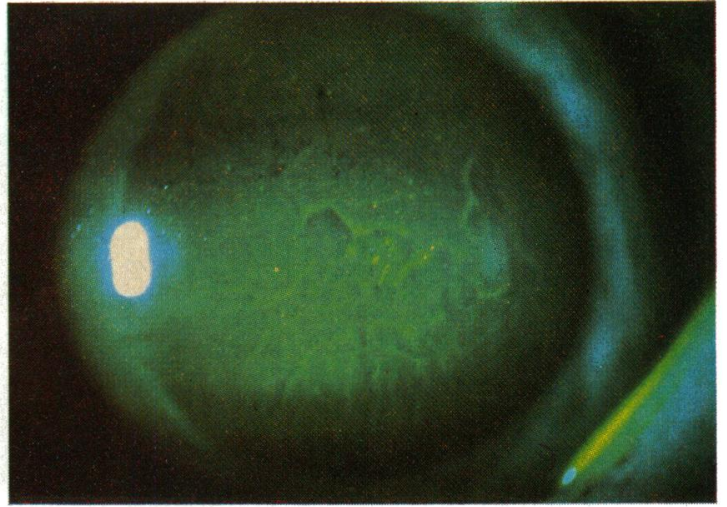

16

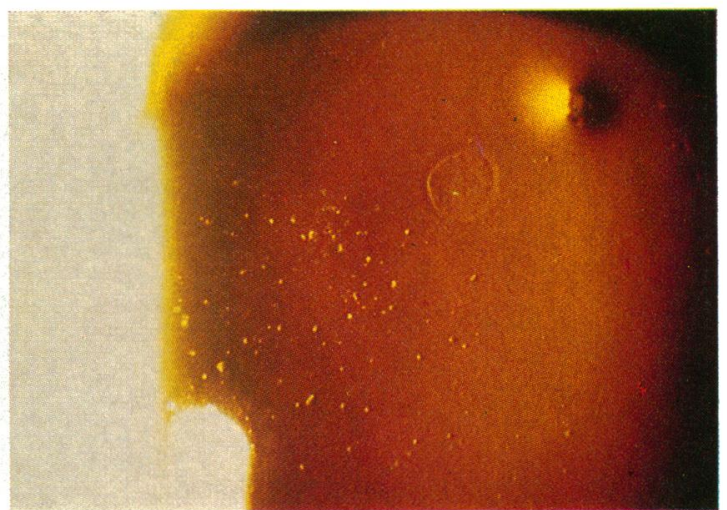

$1 d$

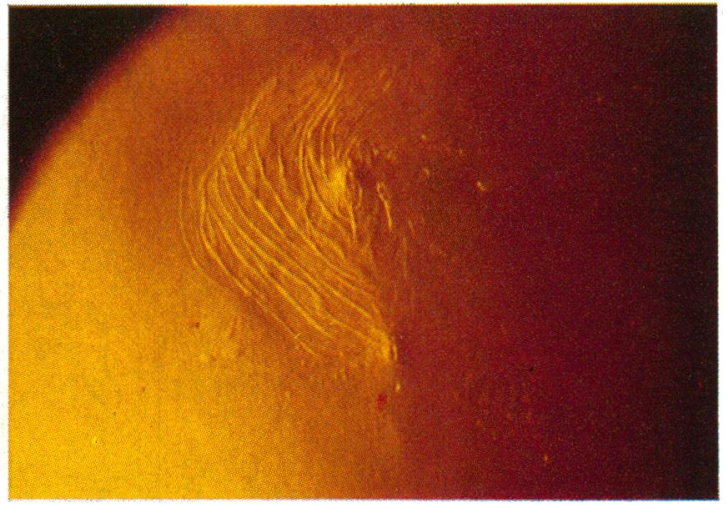

if

Fig. 1 Representative basement-membrane changes seen in patients examined in this study: (a) retroillumination demonstrating a large 'map', (b) fluorescein pattern of the large 'map' shown in Fig. 1a, (c) large map shown in oblique illumination, (d) small 'map', (e) retroillumination of micropseudocysts-'dots'-at high magnification $(\times 8)$, (f) 'fingerprint' lines. 


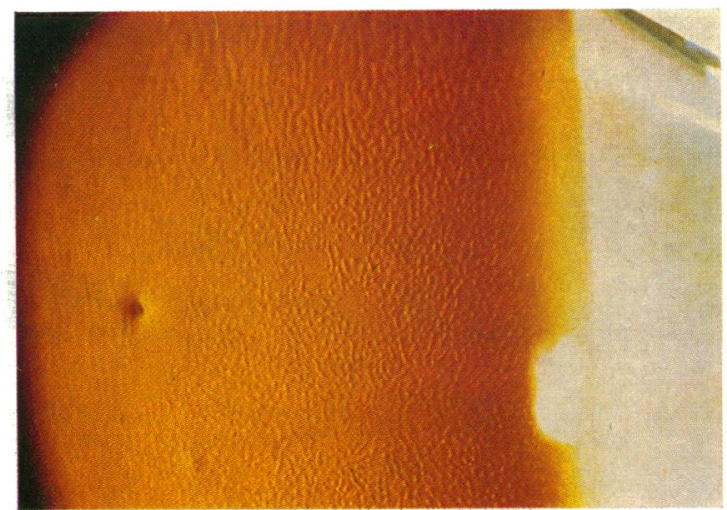

$\lg$

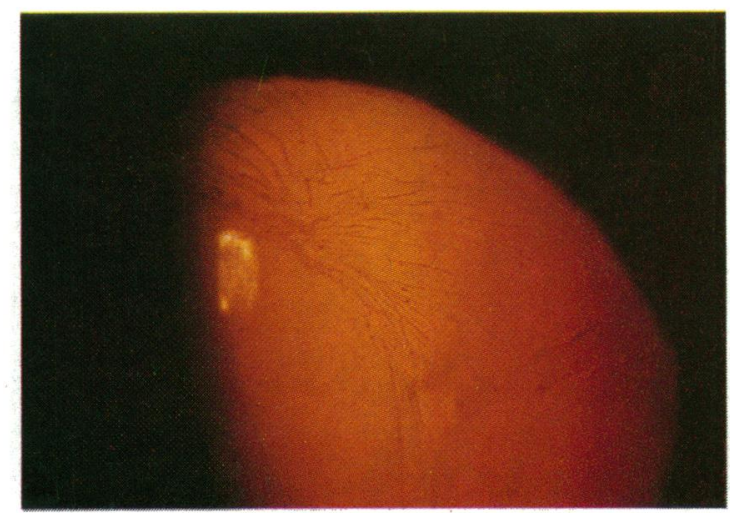

$1 \mathrm{i}$

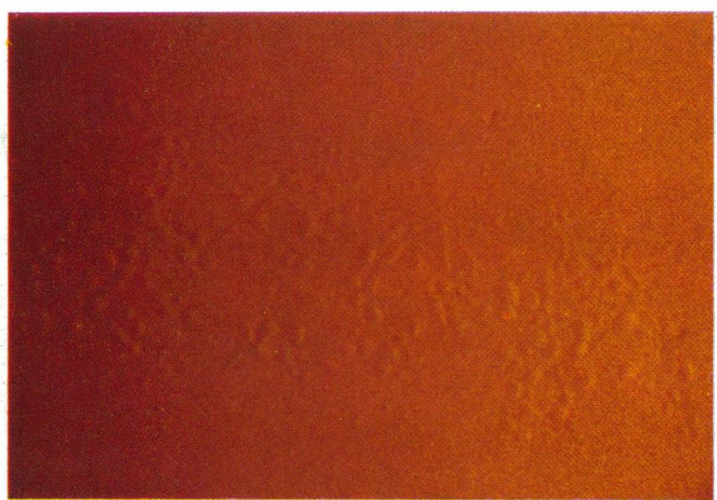

$1 \mathrm{k}$

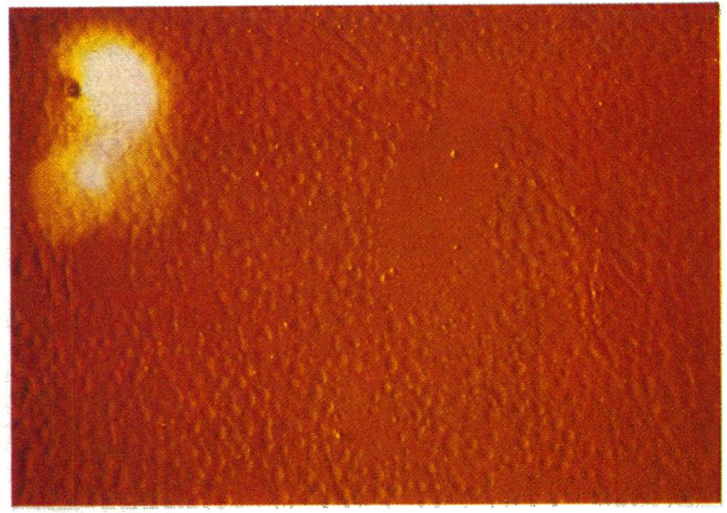

1h

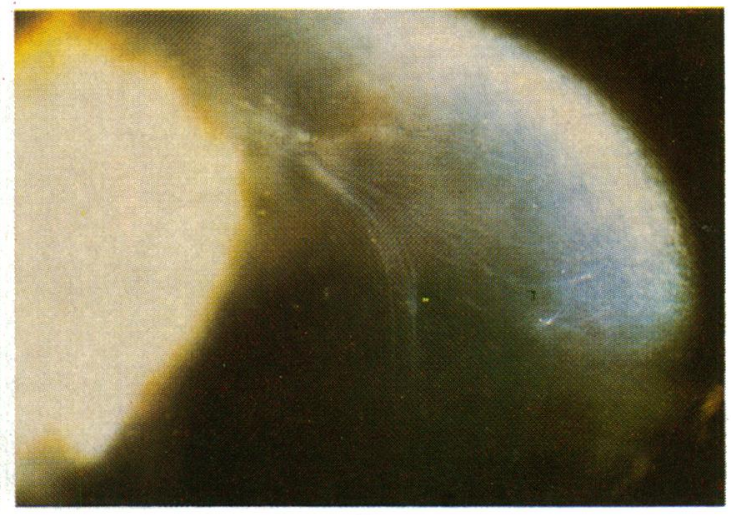

$1 \mathrm{i}$

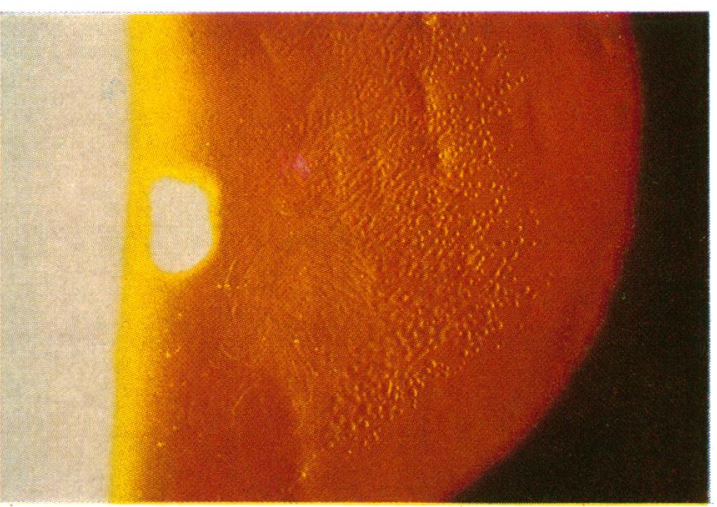

11

Fig. 1 (continued) (g) 'blebs', (h) 'blebs' ( $\times 8$ ), (i) 'mare's-tail' in retroillumination, (j) 'mare's-tail' in oblique illumination, (k) 'nets' $(\times 8)$, (1) 'fingerprint' lines, 'nets', and 'blebs'. 
membrane changes. Of the 38 patients with bilateral basement-membrane abnormalities 31 had corneal maps in one or both eyes. Of these, 24 had other associated basement-membrane changes, such as

Given a particular form of basement-membrane change in one eye, we attempted to analyse the fingerprints or blebs.

frequency of the same change in the second eye of bilaterally affected persons. As can be seen in Table 2, bilaterally affected patients with maps, blebs, or nets tended to have similar types of lesions in both eyes. This tendency was less striking for patients with corneal fingerprints.

We tabulated the geographical locations of the
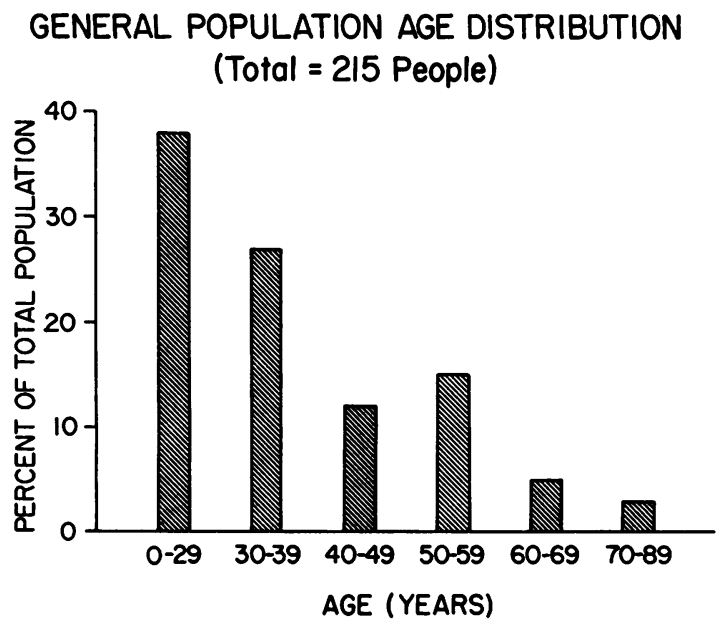

Fig. 2 Age distribution for the 215 people from the general population studied. Abscissa, age groupings; ordinate, percent of total population sample in each age grouping.

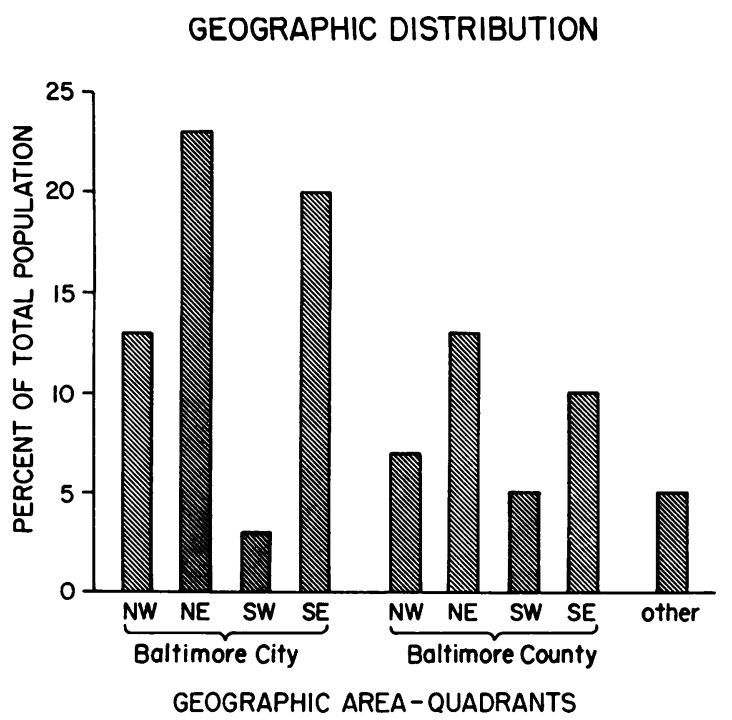

Fig. 4 Geographic distribution of home addresses of the 215 people in the general population studied. Abscissa, the area of Baltimore city and county divided into four quadrants: ordinate, the percent of the population sample living in each of the quadrants shown. 
basement-membrane changes noted in this study (Table 3). It is apparent that the inferior quadrant of the cornea, defined by the 4.30 and 7.30 o'clock meridians, showed a significantly higher prevalence of basement-membrane changes than did the other quadrants $(\mathrm{p}=0.003)$.

From Table 4 it can be seen that there were no major differences in the prevalence of basementmembrane changes between the black and Caucasian groups $(p=0.75)$, and there was no significant difference between the prevalence in males and females $(p=0 \cdot 20)$.

The reasons people gave for volunteering to enter our study are shown in Table 5 . Only $29 \%$ of our sample population felt that they had any problems with their eyes or were worried about their eyes. Within this subgroup of people $45 \%$ had basementmembrane changes. This percentage is essentially

\section{BILATERAL PLUS UNILATERAL BASEMENT MEMBRANE CHANGES}

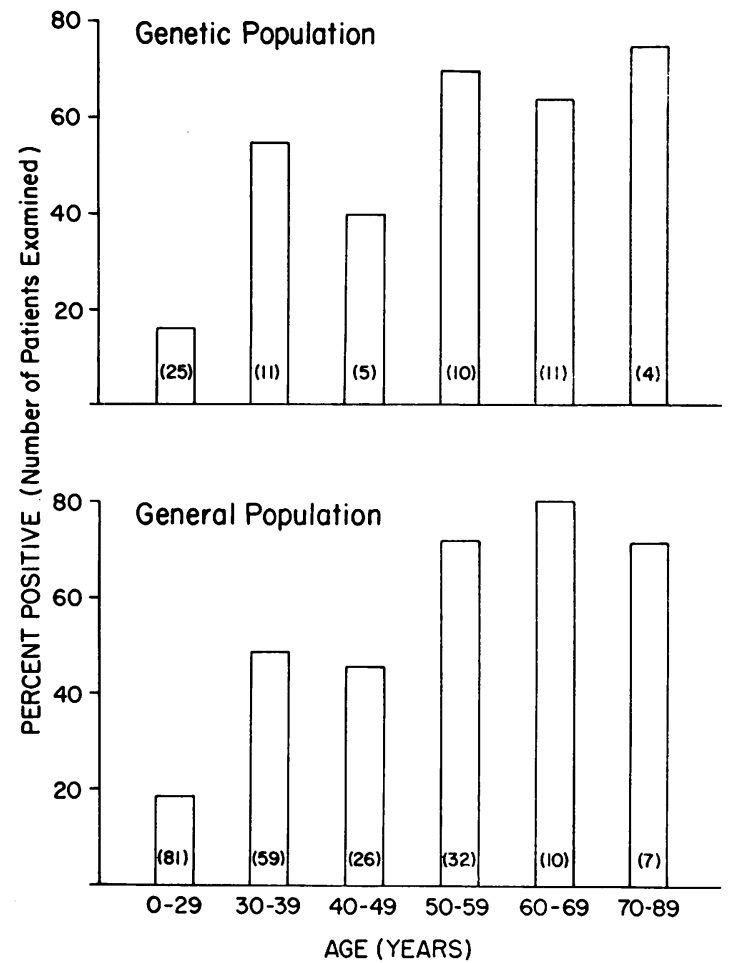

Fig. 6 Prevalence of all these forms of basementmembrane changes in this general population compared to that found in this genetic population. Abscissa, age groupings; ordinate, percent of each age group within the population with basement-membrane changes.

(Figures in parentheses indicate the number of individuals in each age group for the population samples shown.) the same as the $43 \%$ prevalence of basementmembrane changes seen in the asymptomatic portion of our general population in this study.

When questioned directly subjects with basementmembrane abnormalities appeared to have a slightly higher incidence of nonspecific, mild ocular symptoms (Table 6). These did not conform to any disease pattern, and no history of recurrent corneal erosion could be obtained in any of the patients in our general population.

Table 1 General population sample: the form of basement-membrane change found in affected individuals

\begin{tabular}{|c|c|c|c|c|}
\hline \multicolumn{2}{|c|}{ Unilaterally affected (57)* } & \multicolumn{3}{|c|}{ Bilaterally affected (70)*** } \\
\hline $\begin{array}{l}\text { Basement } \\
\text { membrane } \\
\text { changes }\end{array}$ & & $\begin{array}{l}\text { This type } \\
\text { of lesion } \\
\text { in } 1 \text { eye } \\
\text { of pair }\end{array}$ & $\begin{array}{l}\text { Same } \\
\text { lesion } \\
\text { both eyes }\end{array}$ & $\begin{array}{l}\text { Eyes with } \\
\text { multiple } \\
\text { lesions }\end{array}$ \\
\hline Map & 50 & 8 & 20 & 23 \\
\hline Dot (cyst) & 5 & 4 & 1 & 7 \\
\hline Fingerprint & - & 8 & 7 & 18 \\
\hline Bleb & 1 & 5 & 13 & 23 \\
\hline Net & - & 2 & 3 & 6 \\
\hline Other**** & 4 & 3 & 1 & 3 \\
\hline
\end{tabular}

*Number of eyes affected.

*:Eyes with multiple forms of basement-membrane change, at least one of which is of the form shown in the left column.

***:Irregularities in basement membrane not categorised by any of the forms specified in the text.

Table 2 General population sample: similarity of lesions found in eyes of bilaterally-affected individuals

\begin{tabular}{lcc}
\hline Type of lesion & Lesion in either eye & Same lesion in both eyes \\
\hline Map & 31 & 22 \\
Dot (cyst) & 5 & 1 \\
Fingerprint & 15 & 7 \\
Bleb & 18 & 13 \\
Net & 5 & 3 \\
Other* & 4 & 1
\end{tabular}

*Irregularities of basement-membrane change not characterised by any of the forms specified in text.

Table 3 Corneal geographic location of basementmembrane change

\begin{tabular}{lllll}
\hline & & \multicolumn{3}{l}{ Lesion per quadrant } \\
\cline { 3 - 5 } Quadrant (meridians) & Right eye & Left eye & Total \\
\hline Upper $\quad(10.30-1.30)$ & 30 & 27 & 57 \\
Lower $\quad(4.30-7.30)$ & 40 & 41 & 81 \\
Nasal $\quad(7.30-10.30$ or & & & \\
Temporal ( $(1.30-4.30$ & 23 & 32 & 55 \\
& $7.30-10.30)$ & 23 & 18 & 41 \\
\hline
\end{tabular}




\section{GENETIC POPULATION}

There was much similarity in the prevalence of all forms of basement-membrane abnormalities seen in both the genetic and general population samples (Fig. 6). In both groups 70 to $75 \%$ of people over the age of $50(\mathrm{p}=0.08)$ and 45 to $50 \%$ of people between the ages of 30 and $49(p=0.90)$ had basement-membrane abnormalities. In the 0 to 29 age group $18 \%$ of people in both populations were affected $(\mathrm{p}=0.08)$.

There was little tendency for related family members to show the same basement-membrane changes as the probands (Table 7). Possibly the occurrence of corneal maps in several family members in a high percentage of cases is an exception to this rule. However, maps were the most common lesions.

\section{MODE OF INHERITANCE}

To test the hypothesis that these corneal changes represent a dystrophy with an autosomal dominant mode of inheritance we analysed family units consisting of both parents and first-generation progeny, all of whom were examined during this study (Table 8). A gene frequency was calculated from those age groups in which the gene is fully expressed. We assume full gene expression to be the case as soon as the proportion of those affected was constant. This criterion was met in patients over age 50 . The expected number of affected progeny was compared to the observed number of affected progeny, age-dependent penetrance being taken into account. ${ }^{10}$ Chi-square analysis of these data did not allow rejection of the autosomal dominant hypothesis. A second hypothesis, that these corneal changes represent a spontaneous, random degeneration of the cornea, was also tested. The age-dependent prevalence rates for the age groupings in Table 8 were calculated after exclusion of the progeny of the family units just described. Chi-square analysis was then performed comparing expected and observed prevalence rates

Table 4 General population sample: distribution of affected and unaffected individuals

\begin{tabular}{lrlllrl}
\hline & $\begin{array}{l}\text { Unilateral BM } \\
\text { changes* }\end{array}$ & $\begin{array}{l}\text { Bilateral BM } \\
\text { changes }\end{array}$ & No BM changes \\
\hline Caucasian (167) & 41 & $(25 \%)$ & 31 & $(19 \%)$ & 95 & $(57 \%)$ \\
Black (42) & 11 & $(26 \%)$ & 6 & $(14 \%)$ & 25 & $(60 \%)$ \\
Asian (6) & 0 & $(0 \%)$ & 2 & $(33 \%)$ & 4 & $(67 \%)$ \\
$\quad$ Males (83) & 29 & $(35 \%)$ & 11 & $(13 \%)$ & 53 & $(52 \%)$ \\
$\quad \begin{array}{l}\text { Females (132) } \\
\text { General population }\end{array}$ & 25 & $(19 \%)$ & 27 & $(21 \%)$ & 80 & $(61 \%)$ \\
$\begin{array}{l}\text { Total (215)** } \\
\text { Totion }\end{array}$ & 54 & $(25 \%)$ & 38 & $(18 \%)$ & 123 & $(57 \%)$
\end{tabular}

*BM=basement membrane. **Total number of individuals per subgroup.
Table 5 General population sample: subjects' reasons for participation

\begin{tabular}{|c|c|c|c|}
\hline $\begin{array}{l}\text { Reasons stated by } \\
\text { subject }\end{array}$ & $\begin{array}{l}\text { Number of } \\
\text { people }\end{array}$ & $\begin{array}{l}\text { Basement- } \\
\text { membrane } \\
\text { changes } \\
\text { present }\end{array}$ & $\begin{array}{l}\text { Basement- } \\
\text { membrane } \\
\text { changes not } \\
\text { present }\end{array}$ \\
\hline Worried about eyes & 55 & 26 & 29 \\
\hline Problems with eyes & 6 & 2 & 4 \\
\hline Free examination & 56 & 19 & 37 \\
\hline Suitable time & 33 & 18 & 15 \\
\hline To help study & 29 & 15 & 14 \\
\hline Never examined & 15 & 5 & 10 \\
\hline Miscellaneous reasons & 18 & 11 & 7 \\
\hline Unknown** & 3 & - & 3 \\
\hline
\end{tabular}

*Total $=215$. * Persons who did not specify any reason for joining the study.

Table 6 Symptoms described by individuals in the general population sample

\begin{tabular}{lcl}
\hline & $\begin{array}{l}* \text { BM changes present } \\
\text { Number of } \\
\text { patients }=123\end{array}$ & $\begin{array}{l}\text { *BM changes not } \\
\text { present } \\
\text { Number of } \\
\text { patients }=92\end{array}$ \\
\hline No symptoms & 83 & 48 \\
Grittiness & 7 & 9 \\
Burning & 18 & 23 \\
Discharge & 7 & 10 \\
Itchiness & 4 & - \\
Other** & 4 & 2
\end{tabular}

*BMC = Basement membrane. **Described symptoms not related to anterior-segment pathology.

Table 7 Genetic population sample: frequency of morphologic forms of basement-membrane changes within families

\begin{tabular}{llrl}
\hline Form of change & $\begin{array}{l}\text { Basement-membrane } \\
\text { change in proband } \\
\text { (one or both eyes) }\end{array}$ & $\begin{array}{l}\text { Percent of affected } \\
\text { relatives with same } \\
\text { change as proband }\end{array}$ \\
\hline Map & 13 & $71 \%(14) *$ \\
Dot (cyst) & 7 & $17 \%(12)$ \\
Fingerprint & 13 & $20 \%(20)$ \\
Bleb & 1 & $0 \%$ (0) \\
Net & 1 & $100 \%(1)$ \\
\hline
\end{tabular}

*Number of family members with BM changes.

Table 8 Family units used for genetic analysis

\begin{tabular}{|c|c|c|c|}
\hline & Affected* & Affected* & Affected* \\
\hline Number of families & 13 & 3 & 1 \\
\hline \multicolumn{4}{|l|}{ Number of progeny } \\
\hline Age $\quad 0-30$ & 8 (1)*** & $5(0)$ & $3(0)$ \\
\hline Age 30-39 & 4 (3) & 5 (3) & - \\
\hline Age 40-49 & 2 (1) & - & - \\
\hline
\end{tabular}

*Either major or minor basement-membrane changes were considered positive. **Number of affected progeny. 
irrespective of the corneal findings of the parents, and again the null hypothesis could not be rejected. This second hypothesis was also tested by doing chisquare analysis of the age-dependent prevalence data in the 2 populations shown in Fig. 6. Again, chisquare analysis of these data did not allow rejection of the null hypothesis.

\section{Discussion}

Vogt ${ }^{11}$ described the occurrence of corneal basementmembrane dots, and later described ${ }^{12}$ fingerprint lines. The description of these and other lesions was expanded by Guerry. ${ }^{73}$ The spectrum of basementmembrane changes was expanded by Bron and Brown $^{8}$ and Brown and Bron ${ }^{9}$ with the inclusion of net, bleb, mare's-tail, and tramline changes.

These changes represented a spectrum of corneal epithelial basement-membrane abnormalities with a similar pathological basis ${ }^{2} 8$ that often are seen in one or both corneas of a patient. ${ }^{23}$ Histopathologically, aberrant basement membrane has been shown to be a common feature of many of these abnormalities, ${ }^{2} 314$ and aberrant basement membrane has been postulated to predispose to the recurrent erosion syndrome. $^{38}$ The basis for this predisposition is thought to be the absence of good hemidesmosomal attachment complexes between basement membrane and Bowman's layer. ${ }^{2}$ There have been several reports of genetic predisposition to recurrent erosions and to map-dot-fingerprint changes. Franceschetti ${ }^{15}$ reported a family with recurrent erosions of the cornea in which a dominant mode of inheritance could be demonstrated. More recently Laibson and coworkers ${ }^{35}$ have described a dominant mode of inheritance in map-dot-fingerprint dystrophy. However, the prevalence of this condition in the general population remains largely undefined. ${ }^{3} 71314$ It was evident from our early studies that this condition was by no means as rare as previously thought. Because of these data we undertook our general population study.

Map-dot-fingerprint basement-membrane changes were found in $43 \%$ of the general population, including all age groups, and in $76 \%$ of those people over age 50. Our general population sample was biased toward the younger age group (under 30), and toward those in sedentary professions, who are unlikely to be exposed to occupational corneal trauma. This may, if anything, lead to a slight underestimate of the prevalence of map-dotfingerprint changes in the total population.

$25 \%$ of our general population sample had changes in only one eye. Almost all these people had maps unilaterally. This rate of unilateral findings was present in all age categories studied. A possible inter- pretation of these data is that these basementmembrane changes are forerunners of the more diffuse forms of corneal abnormalities seen in older subjects. In support of this hypothesis is the fact that 16 of 38 subjects with fingerprints, dots, blebs, and nets also had map configurations in the cornea.

We observed an $18 \%$ prevalence of bilateral basement-membrane changes in persons over age 50 . These are very conservative estimates of prevalence because most unilaterally affected individuals should probably be counted in these prevalence data. The relatively low prevalence found by Laibson $^{3}$ of approximately $6 \%$ may be explained by the apparent failure to dilate the patients' eyes before examination, despite the recognised difficulty in observing subtle basement-membrane changes without full dilatation and retroillumination.

The inferior quadrant of the cornea between the 4.30 and 7.30 o'clock meridians is generally exposed to more environmental stress (e.g., drying) than the other quadrants. In terms of exposure and of poor tear-film dynamics this area might be expected to undergo a progressive change more rapidly than other areas of the cornea. In fact we demonstrated a significantly higher rate of basement-membrane change in this quadrant $(p=0.003)$.

None of the people examined in our general population had recurrent erosions of the cornea despite the occasionally extensive basement-membrane changes observed. In the genetic population all 18 probands had recurrent erosions, and all but 2 improved concurrently with the topical application of $5 \%$ sodium chloride ointment. The 2 patients who initially required epithelial debridement and soft contact lens application continued to use sodium chloride ointment after their initial acute episode. Thus, it would appear that even patients with recurrent erosive episodes respond quite well both therapeutically and prophylactically to this benign form of medical treatment. It is our impression that patients with this history remain asymptomatic with nightly use of $5 \%$ sodium chloride ointment to prevent the recurrence of erosions.

Because of the high prevalence of these basementmembrane abnormalities genetic analysis of these data is complex. We were unable to establish with certainty whether or not there was a genetic basis for the expression of these corneal basement-membrane changes or whether these abnormalities represent an age-dependent degeneration of the cornea. Because of the complexities of the analysis and the almost universally benign course of this condition it was felt that an exhaustive accumulation of more genetic data was not warranted.

The interrelationship of map-dot-fingerprint changes and recurrent corneal erosions is complex. 
It is not surprising that many patients with recurrent erosive episodes in one eye have basement-membrane abnormalities in the fellow eye, simply because these abnormalities are so common in the general population. Previous attempts at correlating these 2 conditions were based on the misconception that both conditions were relatively rare and that their occurrence in the same individual indicates a causeand-effect relationship. Because it now appears that map-dot-fingerprint basement-membrane abnormalities are extremely common this cause-and-effect relationship requires further study.

We thank Dr Edmond A. Murphy, professor of medicine and biostatistics, Johns Hopkins University, for his help in preparing this manuscript; and we thank Ms Terese Fila for valuable technical assistance, and Mr J. David Andrews, Wilmer Institute, Baltimore, for reviewing the manuscript.

This study was supported in part by USPHS Research Grant EY 02476 (Dr Hirst) from the National Eye Institute, and by a grant from the Muro Pharmacal Labs, Inc., Quincy, Massachusetts.

\section{References}

1 Bron AJ, Tripathi RC. Cystic disorders of the corneal epithelium. Parts I and II. Br J Ophthalmol 1973; 57: 361-90.

2 Fogle JA, Kenyon KR, Stark WJ, Green WR. Defective epithelial adhesion in anterior corneal dystrophies. $\mathrm{Am} \mathrm{J}$ Ophthalmol 1975; 79: 925-40.

3 Laibson PR. Microcystic corneal dystrophy. Trans Am Ophthalmol Soc 1976; 74: 488-531.

4 Kaufman HE, Clower JW. Irregularities of Bowman's membrane. Am J Ophthalmol 1966; 61: 227-30.

5 Laibson PR, Krachmer JHP. Familial occurrence of dot (microcystic), map, fingerprint dystrophy of the cornea. Invest Ophthalmol Visual Sci 1975; 14: 397-9.

6 Luxenberg MN, Friedland BR, Holder JM. Superficial microcystic corneal dystrophy. Arch Ophthalmol 1975; 93: $107-10$.

7 Guerry D, III. Fingerprint-like lines in the cornea. Am J Ophthalmol 1950; 33: 724-6.

8 Bron AJ, Brown NA. Some superficial corneal disorders. Trans Ophthalmol Soc UK 1971; 91: 13-29.

9 Brown NA, Bron AJ. Superficial lines and associated disorders of the cornea. Am J Ophthalmol 1976; 81: 34-51.

10 Murphy EA, Chase GA. Principles of Genetic Counseling. Chicago: Year Book Medical Publishers, 1975: 270.

11 Vogt A. Weitere Ergebnisse der Spaltlampenmikroskopie des vordern Bulbusabschnittes. (Cornea, Vorderkammer, Iris, Linse, vorderer Glaskörper, Conjunctiva, Lindränder). 1. Abschnitt: Hornhaut. Albrecht von Graefes Arch Ophthalmol 1921; 106: 63-103.

12 Vogt A. Lehrbuch und Atlas der Spaltlampenmikroskopie des lebenden Auges. Berlin: Springer, 1930; 1: 264-5.

13 Guerry D, III. Observations on Cogan's microcystic dystrophy of the corneal epithelium. Trans Am Ophthalmol Soc 1965; 63: 320-34.

14 Cogan DG, Donaldson DD, Kuwabara T. Microcystic dystrophy of the corneal epithelium. Trans Am Ophthalmol Soc 1964; 62: 213-25.

15 Franceschetti A. Hereditäre rezidivierende Erosion der Hornhaut. Z Augenheilkd 1928; 66: 309-16. 